\title{
Retranslation and Shifting Constraints
}

\author{
Kerem GEÇMEN ${ }^{*}$
}

The article hereby is an inquiry into a case of translation republishing, where extensive changes in the latter version are present despite the fact that the agents of the process are the same. The case is a fruitful source of discussion for translation studies since it provides constancy of significant variables while the translation products are considerably different. Through a descriptive study of such a case, varying constraints under which the agents operate are attempted to be revealed. Such revelation is also significant insofar as it provides a new perspective on the motives behind retranslation, which has been an amply discussed issue. In addition, the observed change in the constraints leading to non-conformism and a related change of macro-strategy observed in the retranslation seem to provide significant insight into the role of cultural, communicative and contextual factors in translator behaviour, which has important implications for translator training. The analyzed case also provides ground for the reconsideration of some of the common central concepts in translation studies today, as it seems to be buoyed up in the blurry boundaries between these concepts. Such conceptual discussion is increasingly becoming essential for translation studies as the body of research in translation studies calls for more and more precise terminology with each passing day. Keywords: retranslation; self-retranslation; translator training; nonconformism; skopos

\section{Introduction}

The present article seeks to contribute to the discussion on the role of translation constraints (mainly norms and conventions) on translation, which has been an exceedingly debated issue since the introduction of descriptive translation studies, and to the discussion on the possible motives of retranslation by making use of an intriguing case. The rationale behind the selection of the case at hand is that it presents an important opportunity to lay bare many aspects of these two issues thanks to the constancy in many important variables (namely the agents of the translation process, target audience, intended function, time and place). In usual cases there is a substantial degree of variance among these variables each of which has the potential to influence phenomena to a great extent. This variance makes it very difficult to arrive at even tentative explanatory hypotheses even if large corpora of texts and contexts are examined. However, the constancy of many of the important variables in the case at hand provides a level of control of variables which might be likened to experimental settings. This

\footnotetext{
Lecturer at Istanbul Medipol University; $\mathrm{PhDc}$ at Istanbul 29 Mayis University. E-mail: keremgecmen@gmail.com
} 
will hopefully enable the researcher to arrive at more precise and non-trivial explanatory hypotheses.

The present case involves a widely used coursebook on psychological counselling and its ethical/legal dimensions named Standards and Ethics for Counselling in Action (Bond 2010), its Turkish translation named Psikolojik Danışma Uygulamalarında Etik ve Standartlar (Bond 2013), and a retranslation of the same book named Psikolojik Danışmanlıkta Etik ve Yasal Konular (Bond [2016] 2017). ${ }^{1}$ In both the translation and the retranslation, the chief translator (head and supervisor of the translation team) and the editor were the same, and she seems to have acted as an active agent supervising the translation process closely. Both the translation and the retranslation were intended for the same target audience and purpose as explicitly mentioned in the back covers of both translations with the same exact words which indicate that the book is a prospective coursebook for undergraduate students, resource book for graduate students, manual for counselling practitioners, and a reference book for those who are interested in this field. The intended functions are also the same in both versions, as also explicitly stated in the back covers as causing the reader to reconsider what they are doing and to ask themselves the questions "How ethical is what I have been doing?", "How should I act?", They were also produced within a very short period of time, namely a few years, so obviously "times" have not changed. There are only 4 years between the translation and the retranslation, and the latter is not a reprint of the former as it is a substantially different target text. The publishing house is also the same, one which mainly prints coursebooks (both Turkish translations and Turkish originals). So, the first question the present paper attempts to answer is the following: "If the team of translators and editor, publishing house, time frame, target audience, purpose and intended function are all the same, why is the English coursebook published in two considerably different Turkish versions?"

Besides, the retranslation at hand includes major adaptations as observed from close text analysis and as indicated by the editor in both the book cover and the editor preface. However, the production of the second version under the aforementioned circumstances and including many parts of the initial translation seems to involve retranslation, revision, editing,

\footnotetext{
${ }^{1}$ The 2017 version is a reprint of the 2016 version which has also been analyzed and where merely a few negligible differences were observed. Since the 2016 version is out of print and since all the observations are exactly the same in both versions, I consider the two versions to be the same and continue the discussion as if there are two translations (the 2013 translation and the 2017 retranslation) for convenience.

${ }^{2}$ All translations of textual or paratextual content from the Turkish translated book into English are carried out by the present author.
} 
rewriting, intralingual translation, interlingual translation, indirect translation (from the first translation), direct translation (from the English text), self-translation, self-retranslation, selfediting, i.e. many of the concepts commonly considered distinct from one another. Therefore the present paper also attempts to inquire into the question: How can such translational activity be conceptualized or incorporated into translation studies and what does it suggest about the conceptual framework on translation used in Translation Studies.

Through the case study carried out to answer these questions, I will attempt to make the following contributions: (1) to show by example how useful it might be to study retranslations by same translators/teams to reveal constraints ${ }^{3}$ on translation and the relations and interaction among constraints; (2) to emphasize the role of agents in the process of (re)translation as per the current developments in the TS literature (Tahir-Gürçağlar 2009; Paloposki and Koskinen 2010; cf. Merkle 2008; cf. Meylaerts 2008); (3) to point to the limits of underlying unitarian assumptions behind current common concepts in translation studies (and justify a call for increased precisification and operationalisation); (4) showing the usefulness of translators' maximum exposure to the communicative situation and engagement, and its promise in translation education.

The theoretical framework adopted in the present study is a target-oriented one, drawing mainly from Toury's (1995) target-oriented approach. The methodology followed throughout the study was a reconstruction ${ }^{4}$ of constraints through the use of textual and extratextual sources (Toury 1995). As the objects of this study include two versions of the same source text, produced one after the other under the same circumstances, I will use Toury's method of reconstructing constraints through the comparison of successive revisions within a translation process. ${ }^{5}$ Although the two versions here are finalized and published versions, I will take the first one as the interim version since the later version is one that attempts to improve the first version. This can be seen in the way paratextual information conceptualizes this second translation as "improvement", and from the editor's preface where she mentions

\footnotetext{
${ }^{3}$ The concept 'constraint' is used in the Touryian sense in this paper, thus covering rules, norms and idiosyncrasies, (see 1995, 54ff.)

${ }^{4}$ According to Toury, a target-oriented approach justifies and can even be defined by the reconstruction (or "establishing") of constraints, especially norms. Reconstruction here means trying to uncover or making a claim to reveal these constraints, through the evidence observed through descriptive analysis. $(1995,53)$

${ }^{5}$ According to Toury, one can examine the interdependencies of various constraints and of the relative force of different ones by trying to uncover constraints through the investigation of the successive revisions made by a translator while working on a translation. Examining translators' varying solutions in interim versions throughout a translation process is a methodologically valid way to make claims with explanatory power on constraints under which translators operate. (193ff.)
} 
the problem with the first translation: "the original translation of the book published in 2013 attracted attention, but due to its language and Britain-specific content, it caused some difficulties to our undergraduate students" (Bond 2017, v).

In addition, in the analysis of extratextual sources, Ayşe Nihal Akbulut's (2008) approach which emphasizes the importance of self-description in descriptive studies is adopted. According to Akbulut, self-description includes, among many other sources, the translator's notes, comments, explanations, even silence at certain points, and most importantly for this study, translator's prefaces (the preface on translation is written by the editor in this case who seems to have operated as the supervisor of the translation process) and declared identity (translator, translated by, transferred into Turkish by, etc.) (Akbulut 2008, 67). The use of such sources will be important for supporting the arguments of the present article.

Finally, the functionalist approach to translation (Vermeer 1996; Nord 1997) is adopted in the present paper's emphasis on constraints concerning target audience, and the retranslation's move into a skopos oriented strategy.

\section{Reconstruction of Constraints}

When the two translated versions of the coursebook are examined, the substantial difference between the initial constraints followed presents itself explicitly. On the front cover of the 2013 version, the book is described as "translation from the third edition" and the editor is titled "Translation Editor," reviewing and proofreading process. However, on the front cover of the 2017 version, the book is described as "Turkish translation, cultural adaptation and re-editing". Also, in the editor's preface in the 2017 version, the 2013 version is called "original translation" while the 2017 version is called "renewal and improvement through cultural adaptation" in the preface title, and "a renewed edition with adaptation into our culture, improvement and simplification" in the preface content (Bond 2017, v). The discourse of these self-descriptions

\footnotetext{
${ }^{6}$ The title "Translation Editor" is actually a common one in coursebook translations in Turkey, probably because the common practice is to hire a team of academics from a specialized field each member of which translates one or a few chapters and to put an often more experienced and higher titled (usually professor or associate professor) academic in charge of the translation process as a whole. This person's role occasionally includes making any kind of interventions throughout and at the end of the translation process. Unfortunately, there have yet been no studies examining these practices, how the team work is executed, and the specific roles agents play in such processes. Since this is a case study with already a large agenda, the specifics of the collaboration in such processes could not be investigated here.
} 
in translations suggests that constraints concerning the target culture are much stronger in the 2017 version, while they had not been foregrounded in the 2013 version.

Also, a close scrutiny of the textual material confirms the paratextual evidence. ${ }^{7} \mathrm{~A}$ comparison of the two versions on matricial and textual-linguistic levels will attempt to show this in detail.

\subsection{Matricial Constraints}

The matricial constraints under which the agents operated when producing the 2013 version and the 2017 version are attempted to be uncovered in this section. The matricial analysis below shows results that are in line with the discourse in extra-textual self-descriptive sources. Target-oriented constraints regarding the production of an easily readable and comprehensible coursebook and a more relevant and intriguing content for the reader are dominant in the 2017 version; whereas in the 2013 version, even though such a constraint is not completely absent, it is strikingly weaker in force relative to the 2017 version.

2.1.1 Length. The length between the two target texts seems to be very different at first sight, when the number of pages (2013 Ver.: 253; 2017 Ver.: 370) and the page sizes (2013 Ver.: $160 \times 235$ mm 2017 Ver.: $170 \times 240 \mathrm{~mm}$ ) are compared. Although a full page in the 2013 version contains slightly more characters on average (80-85 characters as opposed to 70-75 characters) due to font size and page margins, a rough calculation seems to validate such considerable difference in length (about 850,000 characters as opposed to $1,100,000$ characters including spaces). However, these numbers are misleading because the 2017 version includes considerably more segmentation (and titles spaced and separated from text bulks), larger fonts in bullet-pointed texts, more paragraph segmentation (main points in paragraphs are often separated into distinct paragraphs in 2017 version), larger graphics and tables. So, it would be wrong to suggest any significant difference in length between the two versions. Constraints concerning length seem to be similar in both translations.

2.1.2 Segmentation. As indicated above in describing length, the 2013 version follows closely the paragraph segmentation of the source text whereas the main points in paragraphs are often

\footnotetext{
${ }^{7}$ It is important to note Gideon Toury's warning here that there is always the danger of a divergence between the verbalized constraints, and the constraints followed in translation. That's why close text analysis is essential for the reconstruction of constraints and for the testing of whether the discourse on a translation really reflects the actual constraints under which a translator operated $(1995,55)$.
} 
separated into distinct paragraphs in 2017 version, resulting in more paragraphs but a simpler page layout and increased readability. Also, the sections of the original book were reflected closely in the 2013 version: the number of chapters and sub-sections in both are the same (4 parts and 19 sections in each); whereas sections are reorganized in the 2017 version. Some sections are omitted but mostly, new sections are added (either content-wise or title-wise), and therefore the number of sections is increased (4 parts, 18 sections, and 108 sub-sections). The resulting table of contents is 6 pages in this version as opposed to 1.5 pages in the original and the 2013 version. The constraints concerning segmentation differ significantly in the two versions. While the 2013 version carefully reflects the exact segmentation of the original book, the 2017 version seems to have focused on providing a more easily readable and more comprehensive coursebook by organizing text bulks under more headings (which are specific and descriptive/explanatory). This seems to be an attempt to make it easier for the reader to follow the text, to remember at all times where he/she is and to be reminded of how each point relates to its superordinate point or topic. Hence, it would be safe to say that while the 2013 version is fully influenced by the source text oriented constraint of following closely the segmentation of the original text, the 2017 version is considerably influenced by the targetoriented constraint of providing the reader with an easily comprehensible coursebook.

2.1.3 Additions \& Omissions. In line with the cultural adaptation strategy described by the editor, there are large omissions and additions in 2017 version, while the 2013 version merely adds 21 question boxes and makes no omissions. The target-oriented constraint of increasing reader comprehension can be observed in the 2013 version to a certain limited level. However, the relative force of this constraint is a lot higher in the 2017 version, because it makes extensive omissions of content unique to the British setting such as laws, standards, cited references, institutions etc. and extensive additions of content about the Turkish setting where laws, standards, reference material, institutions, example cases etc. that are relevant to the points given in the original book exist in the Turkish setting. In addition, the focus point of each paragraph is provided in margin notes next to the paragraphs, apparently to make it easier to follow and comprehend the text. Also, the number of question boxes aimed usually at engaging the reader in coursebooks is higher (26 question boxes), and each section is provided with a section outline as per coursebook conventions for instructional purposes. Moreover, 3 boxes containing information on Turkish legislations and 22 paragraphs containing 
information on the activities and standards of Turkish Psychological Counselling and Guidance Association (Türk PDR Derneği) are included in different parts of the text where they are relevant to the issue dwelt on by the source text. Furthermore, many sentences adding to the content of the book especially with regard to the needs of the Turkish audience are provided within the relevant parts of the text. So, despite the fact that the total length of two versions are not different to a notable extent, the textual material used in the target texts differ considerably in parts where intervention seems to be considered beneficial. These omissions and additions will also be discussed under the section "Textual-Linguistic Constraints."

To sum up, while there are no omissions and very few additions in the 2013 version in line with a source-oriented constraint regarding informational transfer, the 2017 version makes extensive omissions and additions as per the target-oriented constraint regarding the provision of a more instructive, relevant and easily comprehensible coursebook for the target audience.

2.1.4 Layout and Visual Special Features. The page layout and visual special features present in the two versions are also significantly different. The 2013 version follows closely the page layout, colours (black and white), bulleting and spacing of the original book whereas the 2017 version is more colourful (including various shades of blue in headings and sub-headings, bullet points, etc.), the page layout is much more spacious, and bullet points are increased to improve visual outlook. Also, some lists are converted into tables. It is quite apparent that the constraint to appeal to the target audience had much more relative force in the preparation of the 2017 version when compared to the 2013 version, which includes merely jigsaw puzzle parts on chapter beginnings (a symbol taken from the title of the original book).

\subsection{Textual-Linguistic Constraints}

2.2.1 Use of Language. Although it was indicated in the editor's preface that the use of language in the 2013 version caused some difficulty for undergraduate students and that the 2017 version involves simplification, a textual comparison between the two versions do not reveal notable simplification in the 2017 version in terms of language use. The content that is not added or omitted in both versions is mostly the same textual material, with minor changes in 2017 in terms of removing several major source language interferences, such as the use of 
subject pronouns ${ }^{8}$ and the suffix "-sel." It also includes slight revisions of the tense sequence and voice. ${ }^{10}$ However, these minor changes do not make a notable difference in terms of linguistic simplification. The 2017 version includes simplification in aspects other than language use. This is the subject of the next section. To sum up, there is no notable difference in the relative force of constraints on the simplicity of language use.

\subsubsection{Simplicity vs. Complexity. A constraint regarding offering a simpler target text in terms} of content seems to manifest itself in the 2017 version, whereas the 2013 version seems to be guided by a source-oriented constraint regarding transferring the informational content of the source text as accurately as possible. The simplicity seemingly aimed at the 2017 version is most apparent in the translation of detailed informational content concerning the source culture. For example, in the translation of the following sentence, such content (as underlined for emphasis by the present author) is transferred in the 2013 Version but simplified by a generalization in the 2017 version:

Source Text:

The main codes of standards and ethics of use to counsellors in Britain are published by the British Association for Counselling and psychotherapy, the British Psychological Society, the Confederation of Scottish Counselling Agencies, the Irish Association for Counselling and Psychotherapy, and the United Kingdom Council for Psychoteraphy. (Bond 2010, 230)

2013 Version:

İngiltere'de psikolojik danışmanlar tarafından kullanılabilecek temel etik ilkeler ve standartlar; İngiliz Psikolojik Danıșma ve Psikoterapi Derneği, İngiliz Psikoloji Birliği, İskoç Psikolojik Danıșma Kurumları Konfederasyonu, İrlanda Psikolojik Danışma ve Psikoterapi Derneği ve Birleșik Krallık Psikoterapi Konseyi [all the institution names are translated] tarafından yayınlanmıştır. (Bond 2013, 218)

2017 Version:

İngiltere'de psikolojik danışmanlar tarafından kullanılabilecek temel etik ilkeler ve standartlar; ilgili meslek örgütleri [relevant professional organizations] tarafindan yayınlanmıştır. (Bond 2017, 274)

\footnotetext{
${ }^{8}$ The subject pronoun is rarely used in idiomatic, natural Turkish unless the subject is supposed to be emphasized. The grammatical person of the subject is already marked by the predicate in the form of an inflection. It is usually as a result of literal translation, i.e. an interference of the source language that Turkish target texts contain subject pronouns in sentences where the subject is not intended to be emphasized.

${ }^{9}$ A suffix that tends to be used more frequently in translated texts as it is a counterpart of the adjective-making suffix "-al" in English. It occasionally results in unnatural wording in the 2013 version such as "etiksel" (the correct adjective form for "ethical" is "etik" in Turkish.)

${ }^{10}$ In formal Turkish, especially in legal language and the language of education materials, it is a lot more common to use passive voice, and the 2017 version follows this target language norm.
} 
Various content that can be considered specific to the British culture to the point of being relatively irrelevant or that can be argued to include a significant amount of detail at the expense of making the text difficult to follow was simplified, shortened or generalized by the 2017 version, apparently to ensure a more seamless reading experience. Such a constraint is not observed in the 2013 version.

In short, the 2017 version is guided by a target-oriented constraint of keeping the coursebook simple for the target audience. The 2013 version on the other hand, seems to be guided by a constraint of accurate information transfer. The two versions seem to be governed by significantly differing constraints in terms of this aspect too.

2.2.3 Reference to Legislation and Institutions. In terms of the translation of legal or institutional references in the source text, a significant difference between the constraints guiding the translations is apparent. In the 2013 versions, all references of the source text remain intact while the 2017 version includes abundant references to the legislation and institutions in the target culture. The extensive additions and omissions described in section 2.1.3 was also largely due to this aspect. The most frequently repeated example of varying strategies concerning the translation of such references is the difference between the 2013 Version's invariable use of BACP (British Association for Counselling and Therapy) as opposed to the 2017 Version's occasional use of either BACP or Türk PDR Derneği depending on the appropriateness of referring to Türk PDR Derneği in the respective context. Therefore, in terms of the translation of references to legislation and institutions, the 2017 version seems to be guided by target-oriented constraints regarding cultural/contextual relevance and comprehensibility whereas the 2013 version seems to be guided by the sourceoriented constraint of transferring the informational content present in the source text.

2.2.4 Works Cited. Needless to say, there are many works cited in the original coursebook. The 2013 version transfers all the English citations present in the original, translating their titles into Turkish in parenthesis, while the 2017 version occasionally replaces them with reference works in Turkish where content is considered appropriate, sometimes adding in-text citations throughout the content where a relevant Turkish source is present. ${ }^{11}$ See the

\footnotetext{
${ }^{11}$ A separate reference section for these Turkish sources is also provided at the end of the book. This reference section not only includes the works cited throughout the text but also other sources that might be beneficial to the reader. The title of this reference section is "Turkish Sources on Ethics", as suggestive of this fact.
} 
following example (work title and author information on the cited works are hereby underlined for emphasis by the present author; the square brackets belongs to the translator).

2013 Version:

Hukukun uygulamayı nasıl etkilediğini tam olarak görebilmek için Bond ve Mitchels tarafindan yazılan Confidentiality and Record Keeping for Counselling and Psychotherapy [Psikolojik Danışma ve Terapi için Gizlilik ve Kayıt Tutma (2008)] adlı kaynağa bakınız. (151)

2017 Version:

Hukukun uygulamayı nasıl etkilediğini tam olarak görebilmek için bu alanda A. E. Gümüș ve M. A. Gümüș tarafindan yazılan "Psikolojik Danıșmada Etik ve Hukuk (2013)" adlı kaynağa başvurulabilir. (185)

2.2.5 Proper Names. The original book makes frequent use of scenarios to discuss possible ways to act in various situations. The English proper names present in these scenarios remain the same in the 2013 version, while in the 2017 version they were all replaced by Turkish names with similar spelling. The English name Douglas becomes the Turkish name Doğan, Sally becomes Sercan, David becomes Davut etc. The variance between constraints is also obvious in terms of the translation of proper names.

2.2.6 Appendices. The appendices of the two versions are considerably different along similar lines. The source text provides a single appendix named "Useful Resources" (Bond 2010, 245-249) where it provides the names and contact information of professional associations such as BACP in Leicestershire, specialized information sources such as The Children's Legal Centre in Essex, and regulatory bodies such as the HPC in London. The 2013 version gives the same content, under the Turkish title "Faydalı Kaynaklar" (Useful Resources), translating only the names of these institutions or sources into Turkish. Source-oriented constraints are quite explicit here. On the other hand, the 2017 version provides eight appendices, none of which include those organizations. Instead these appendices are full of information that are considered relevant to the target audience and appropriate to be included in a coursebook on psychological counselling. ${ }^{12}$ To sum up, the significant difference of constraints presents itself in the appendices of the two versions as well.

\footnotetext{
12 The appendices include a suggested course syllabus, Turkish resources on ethics and counselling (Turkish works cited and other useful Turkish works), Turkish books on work ethics in psychological counselling and guidance, suggested activities and exercises, sample test questions, ethical dilemma examples, translation of the ethical principles of ASCE (American School Counsellor Association) by a different translator and professional associations working on psychology and psychiatry in Turkey (Bond 2017, 309-358).
} 


\subsection{Discussion}

As the descriptive textual analysis presented above clearly shows, the self-description of the editor in the preface accurately represents the textual content. The adaptation strategies are carried out consistently in the 2017 version to create a culturally relevant, simple and improved coursebook for Turkish audience. The explanation to the question "Why is the English coursebook published in two considerably different Turkish versions despite the team of translators and editor, publishing house, time frame, target audience, purpose and intended function are all the same" seems to be the substantial increase in the relative force of the target-oriented constraints and the substantial decrease in the relative force of source-oriented constraints. The source-oriented constraints here seem to arise from the predominant notion of translation favouring source-oriented strategies, as such strategies are not in accordance with the purpose explicitly stated in the back cover of both versions: "a prospective coursebook for undergraduate students, resource book for graduate students, manual for counselling practitioners, and reference book for those who are interested in this field" (Bond 2013; Bond 2017). It seems that the label 'translation' and the conception it brings about have foregrounded source-oriented constraints to such a strong level that even when the purpose of the target text was crystal clear and explicitly stated by the agents in the back cover all along, the appropriate strategy could not be embraced until the conceptualization of the process changed from 'translation' to 'adaptation,' causing the 2013 version, that is, the so-called “original translation" $(2017, \mathrm{v})$, to be governed mainly by the source-oriented constraints imposed by this label to the extent of failing to produce a sufficiently relevant, comprehensible and instructive text.

From this, I would like to cross the descriptive boundaries into the evaluative realm and argue that there is a lack of success in the 2013 version in terms of fulfilling the function the translated text was supposed to fulfil. After all, as mentioned above, the purpose of the translation was explicitly stated in the back covers of both versions as providing "a prospective coursebook for undergraduate students, resource book for graduate students, manual for counselling practitioners, and reference book for those who are interested in this field".

In this regard, this case seems to be a living example corroborating the functional approaches, specifically Skopos Theory by Vermeer (1996). A translation strategy that was 
not Skopos oriented seems to have failed to a notable extent, being replaced by a Skopos oriented translation strategy. After all, the purpose stated in the back cover of both versions seems to require a translation along the lines of the 2017 version. So, from a functionalist perspective, the case is exceedingly suggestive.

Also, I would like to emphasize the successful decisions taken by the agents in the process of moving from the 2013 version to the 2017 version with a view to make a point on the relatively neglected importance of agency (Tahir-Gürçağlar 2009) in studies on retranslation. As Tahir-Gürçağlar (2009) warns us, there is a "risk of overlooking the human element" in the retranslation process (236). Retranslation has long been dominated by the notions of completion and ageing, seen primarily as a direct result of changes in social norms and ideologies, arising out of struggle and competition with previous translations, or similar essentialistic or social-deterministic mechanisms. However, the present case contributes to the line of thinking which emphasizes the agency of individuals (Tahir-Gürçağlar 2009; Paloposki and Koskinen 2010; cf. Merkle 2008; cf. Meylaerts 2008) by providing an example where agents involved in the translation process take different decisions while working under the same external restrictions in two different real life scenarios, concluding the process by acting as non-conformists in the retranslation process. ${ }^{13}$ It seems that the mere experience of seeing the difficulties their students faced while they made use of the book helped them violate the dominant translational norms and act as non-conformists (Toury 1980). ${ }^{14}$

Nevertheless, it is also important to note here that the prevalent narrow notion of translation was not put away in this case, and would have probably prevented the translation team from taking the so-called liberty to make the strategic decisions that yielded the 2017 version if moving to the 'adaptation' label had not been possible for commercial reasons or reasons concerning translation policy or patronage. The very possibility of acting as nonconformists seems to have depended on the removal of the label 'translation,' which is a sad thought from a translation studies perspective.

However, leaving this daunting meta-linguistic issue for the final section where concepts of translation studies will be discussed in detail, I would like to point out to the fact that this case of non-conformist practice shows us the importance of a sufficient awareness of

\footnotetext{
${ }^{13}$ It is important to note here that it is explicitly stated in the prologue to both versions that neither the editor nor the translators claimed any payment for these tasks, donating all their income from the translations to Turkish Psychological Counselling and Guidance Association (Türk PDR Derneği) (Bond 2013; Bond 2017). This indicates that they are free from many important external restrictions.

${ }^{14}$ See Geçmen (2018) for a small-scale discussion on the non-conformity of the case.
} 
the communicative situation in which translation will be placed. Moving from this point, which I believe the present case demonstrates, I would like to suggest a possible method of training translators as non-conformists to be, as a humble contribution to Toury (1980). In addition to the methods suggested by Toury in his article on the issue, and also in line with the functionalist framework in translator training which emphasizes the awareness of the extratextual factors of the communicative situation (Nord 1997), I would like to suggest that making student translators experience the communicative situation and especially the reception of the target text and response of the target audience might be a good method both towards achieving what Toury (1980) calls the "more developed and diversified version of translation competence" (191) and towards achieving the instructional goals set by the functionalist approach, namely to take into account the extratextual factors concerning the communicative situation and to take purpose as the prime determiner of translation strategy (Nord 1997).

\section{Concepts in Translation Studies}

In this section, I will attempt to discuss what the present case has to show concerning the concepts commonly used in translation studies, as the 2017 version in this case seems to lie on the very boundaries of many concepts employed in the discourse on translation.

First of all, the 2017 version seems to be in a hybrid status between interlingual and intralingual translation as it involves interlingual translation from the original as well as intralingual translation from the 2013 version. This poses questions on the common understanding of retranslation as an interlingual translation activity of translating from the ultimate source. As Alvstad and Assis Rosa (2015) point out, not only intralingual retranslation is possible but also it can occur in combination with interlingual retranslation. They conceptualize such cases as "compilative inter- and intralingual retranslation" (17). The 2017 version seems to fall in this category, questioning, in line with Alvstad and Assis Rosa (cf. Peng 2017), the understanding of interlingual and intralingual translations as binary oppositions as well as questioning the common assumption that retranslation is interlingual.

This 2017 version also casts doubt on the present notion of indirect (relay) translation as it is defined as a process involving three languages both in the Routledge Encyclopaedia of Translation Studies (Baker and Saldanha 2009) and Dictionary of Translation Studies (Shuttleworth 1997). After all, an intermediary text acting as an intermediary source text is 
present. If what the notion of indirect translation provides us is the ability to name intermediacy-involving processes, the present definitions should be revised. However, it is also possible to keep the definitions intact and exclude intralingual retranslation.

This brings us to the issue of the position of retranslation in this picture, when the possibility of intralingual retranslation is allowed; retranslation, editing, revision and even proofreading would be qualitatively the same and they can merely be quantitatively different, which is still problematic due to a vagueness problem, i.e. the indeterminacy of the boundaries between these four concepts. (cf. Paloposki and Koskinen 2010)

Also, the 2017 version can be seen as self-retranslation, since it is a retranslation based on a translation produced by the same agents. This would be problematic for the common conception of self-translation as an author's original writing in a different language (Grutman and Van Bolderen 2014). While conceptualizing the 2017 version as self-revision or selfediting is also possible, it does not solve the problem due to the fact that the aforementioned indeterminacy of boundaries between retranslation and revision or editing would map into a similar indeterminacy between self-retranslation and self-revision or self-editing (cf. Güneş 2018).

There are also the issues of translation and adaptation (cf. Raw 2012), whether adaptation is translation, and if not, how to distinguish them.

These conceptual complexities could probably be propagated. The relative success of even the most central concepts of translation studies to map phenomena and facts revealed by descriptive studies seems to be considerably low. The case presented in this study is not an astonishingly special one in that regard. The increasing body of research in translation studies seems to call for a more precise terminology. Creating new terms is always an option, but it could be wiser to first make the presently used concepts much clearer through a process of "precisification" (LaPorte 2004) similar to the one astronomy famously went through with the concept 'planet'. 


\section{References}

Akbulut, Ayşe Nihal. 2008. “Çeviride Özbetimlemenin Önemi.” Litera 21 (1): 1-19.

Alvstad, Cecilia, and Alexandra Assis Rosa. 2015. "Voice in Retranslation: An Overview and Some Trends." Target 27 (1): 3-24.

Baker, Mona, and Gabriella Saldanha, eds. 2009. Routledge Encyclopedia of Translation Studies. 2nd ed. New York: Routledge.

Bond, Tim. 2010. Standards and Ethics for Counselling in Action. Los Angeles: Sage Publications.

- 2013. Psikolojik Danışma Uygulamalarında Etik ve Standartlar. Translated by Binnur Yeşilyaprak. Ankara: Nobel Akademik.

—. 2016. Psikolojik Danışmanlıkta Etik ve Yasal Konular. Translated by Binnur Yeşilyaprak. Ankara: Nobel Akademik.

—. 2017. Psikolojik Danışmanlıkta Etik ve Yasal Konular. Translated by Binnur Yeşilyaprak. Ankara: Nobel Akademik.

Geçmen, Kerem. 2018. "Retranslation, Agency and the Interplay between Conflicting Constraints: A Case of Non-Conformist Self-Retranslation." Paper presented at the Enriching Translation Studies through Rereadings Symposium, Istanbul, March 28.

Grutman, Rainier and Trish Van Bolderen. 2014. "Self-Translation." In A Companion to Translation Studies, edited by Sandra Bermann and Catherine Porter, 323-332. West Sussex: Wiley Blackwell.

Güneş, Alper Zafer. 2018. "Retranslation: What Is in a Concept?" Paper presented at the $5^{\text {th }}$ International Asoscongress, Istanbul, October 26.

LaPorte, Joseph. 2004. Natural Kinds and Conceptual Change. New York: Cambridge University Press.

Merkle, Denise. 2008. "Translation Constraints and the 'Sociological Turn' in Literary Translation Studies." In Beyond Descriptive Translation Studies: Investigations in Homage to Gideon Toury, edited by Anthony Pym, Miriam Shlesinger and Daniel Simeoni, 175-186. Amsterdam: John Benjamins.

Meylaerts, Reine. 2008. "Translators and (Their) Norms: Towards a Sociological Construction of the Individual". In Beyond Descriptive Translation Studies: Investigations in Homage to Gideon Toury, edited by Anthony Pym, Miriam Shlesinger and Daniel Simeoni, 91-102. Amsterdam: John Benjamins.

Nord, Christiane. 1997. Translating as a Purposeful Activity: Functionalist Approaches Explained. Manchester: St. Jerome. 
Paloposki, Outi and Koskinen, Kaisa. 2010. "Reprocessing Texts: The Fine Line between Retranslating and Revising". Across Languages and Cultures 11 (1): 29-49. doi:10.1556/Acr.11.2010.1.2.

Peng, Wenqing. 2017. "Self-Retranslation as Intralingual Translation: Two Special Cases in the English Translations of San Guo Yan Yi". Language and Semiotic Studies 3 (2): 110-127. Jiangsu: Soochow University Press.

Raw, Laurence. 2012. Translation, Adaptation and Transformation. London: Continuum.

Shuttleworth, Mark. 1997. Dictionary of Translation Studies. New York: Routledge.

Tahir-Gürçağlar, Şehnaz. 2009. "Retranslation.” In Routledge Encyclopedia of Translation Studies, edited by Mona Baker and Gabriela Saldanha, 233-236. London: Routledge.

Toury Gideon. 1980. "The Translators as a Nonconformist-to-Be, or: How to Train Translators So As to Violate Translational Norms." In Angewandte Übersetzungswissenschaft: Internationales Übersetzungswissenschaftliches Kolloquium an der Wirtschaftsuniversität Århus, edited by Sven-Olaf Poulsen and Wolfram Wills, 180-194. Arhus: Arhus.

1995. Descriptive Translation Studies and Beyond. Amsterdam: John Benjamins.

Vermeer, Hans J. 1996. A Skopos Theory of Translation: Some Arguments for and against. Heidelberg: TEXTconTEXT. 